\title{
ANÁLISE DA ESTABILIDADE DE CIANETO LIVRE EM MANIPUEIRA PARA UTILIZAÇÃO EM MANEJOS FITOSSANITÁRIOS DE PRAGAS E DOENÇAS
}

Guilherme de Resende Camara*

Fábio Ramos Alves**

Willian Bucker Moraes***

RESUMO: A manipueira, resíduo líquido extraído da mandioca (Manibot esculenta L.) durante o processo de fabricação de farinha e (ou) amido, possui em sua composição glicosídeos que em associação com a enzima linamarase são convertidos em linamarina e lotaustralina formando, assim, compostos cianogênicos (ácido cianídrico e cianeto livre), ambos de caráter ácido e tóxico. As características químicas e orgânicas da manipueira possibilitam a sua utilização no manejo fitossanitário de plantas agrícolas, objetivando reduzir as populações de patógenos a níveis inferiores àqueles capazes de causar perdas. No entanto, apesar do avanço nas pesquisas, pouco se conhece a respeito da estabilidade do cianeto livre $(\mathrm{CN})$ na manipueira após sua liberação. Objetivou-se com o presente estudo avaliar a estabilidade do cianeto livre (CN) na composição da manipueira, visando auxiliar pesquisadores e produtores no uso mais eficiente e racional deste resíduo. Conclui-se que a manipueira possui estabilidade variável do cianeto livre $(\mathrm{CN})$ em sua composição, dentro do período avaliado, independente da forma de armazenamento. Os maiores teores de $\mathrm{CN}^{-}$ foram observados durante as primeiras 24 horas após a extração da manipueira, sendo este o melhor período para sua utilização em manejos fitossanitários de pragas e doenças.

PALAVRAS-CHAVE: Ácido cianídrico; Controle alternativo; Manihot esculenta L.; Tucupi.

\section{THE STABILITY OF FREE CYANIDE IN CASSAVA WASTEWATER IN PHYTOSANITARY MANAGEMENTS AGAINST PESTS AND DISEASES}

\footnotetext{
ABSTRACT: Cassava (Manibot esculenta L.) wastewater, produced during flour or starch processing, contains glycosides which, associated with linamarase enzyme,

"Doutorando em Produção Vegetal pela Universidade Federal do Espírito Santo - UFES, Vitória, ES, Brasil.

** Docente do Departamento de Agronomia da Universidade Federal do Espírito Santo - UFES, Vitória, ES, Brasil.

**** Docente do Departamento de Agronomia da Universidade Federal do Espírito Santo - UFES, Vitória, ES, Brasil.
} 
is converted into linamarin and lotaustralin, forming acidic and toxic cyanogenic compounds (cyanhydric acid and free cyanide). The chemical and organic characteristics of cassava wastewater make possible its use in plants' phytosanitary management to reduce pathogen populations at levels which are lower than those capable of causing losses. Although there has been a lot of progress, there is scanty knowledge on the stability of free cyanide (CN-) in cassava wastewater after its release. Current study evaluates the stability of free cyanide in cassava wastewater to help researchers and producers in the efficient and rational use of the residue. Results show that cassava wastewater has variable stability of free cyanide in its composition during the analyzed period, regardless of storage mode. High $\mathrm{CN}$ - rates were reported during the first $24 \mathrm{~h}$ after wastewater extraction. It is the best period for use in phytosanitary managements against pests and diseases.

KEY WORDS: Cyanhydric acid; Alternative control; Manibot esculenta L.; Tucupi.

\section{INTRODUÇÃO}

A manipueira, resíduo líquido de composição variável extraído da mandioca (Manibot esculenta L.) durante o processo de fabricação de farinha e (ou) amido, possui em sua composição glicosídeos que são convertidos em linamarina e lotaustralina, dos quais se origina o ácido cianídrico (HCN) (CASSONI; CEREDA, 2011), que, em água, pode ser encontrado em sua forma molecular como ácido cianídrico ou na sua forma livre, como íon cianeto (CN) (LINARDI, 2000). São estes os compostos responsáveis pelos efeitos fitossanitários positivos deste resíduo e que possibilitam sua utilização em programas de manejo fitossanitários de pragas e doenças (PONTE, 1999).

Os impactos ambientais causados pela deposição inadequada da manipueira estão relacionados com a composição química e ao considerável volume de resíduo líquido gerado, aproximadamente 250 litros por tonelada de mandioca processada (ralada e prensada) (CEREDA, 2001; FURLANETTO et al., 2011), os quais são comumente descartados a céu aberto, em lagos de deposição ou diretamente em córregos de água, gerando graves impactos ambientais (BALDIN et al., 2012).

As características químicas e orgânicas da manipueira possibilitam a sua 
utilização na agricultura como adubo orgânico em fertirrigação e como herbicida no controle de plantas daninhas (FURLANETTO et al., 2011). Além disso, a manipueira também pode ser empregada no manejo fitossanitário de pragas e doenças como um método de controle alternativo ao uso de agrotóxicos, promovendo diretamente a redução de populações de patógenos a níveis inferiores àqueles capazes de causar danos e perdas em plantas exploradas economicamente (PIMENTA; CARNEIRO, 2005; GONZAGA et al., 2008; FURLANETTO et al., 2011) e, também, contribuindo para a destinação final deste resíduo, redução dos custos de produção pela menor dependência de insumos agrícolas e redução dos impactos ambientais decorrentes desta atividade econômica.

No Brasil, importantes trabalhos evidenciam resultados positivos do uso da manipueira no manejo fitossanitário de diferentes patógenos em diferentes patossistemas, os quais incluem Meloidogyne spp. em Solanum lycopersicum (NASU et al., 2010), Scutellonema bradys em Colocasia esculenta (ALVES et al., 2006; ALMEIDA et al., 2007), Heterodera glicines em Glycine Max (COMERLATO, 2009), M. incognita em Daucus carota (BALDIN et al., 2012), Carica papaya (DAMASCENO et al., 2008) e Glycine Max (FONSECA, 2016), Oidium sp. em Spondias purpurea (FREIRE, 2001), Spodoptera frugiperda em Zea mays (SILVA; SOUZA; SILVA, 2017) e em Dysmicoccus sp. (PRATIS et al., 2013).

No entanto, apesar dos avanços nas pesquisas que acabam por motivar o uso desta nova e promissora forma de manejo fitossanitário de pragas e doenças em cultivos agrícolas como um método de controle alternativo ao uso de agrotóxicos a campo, pouco se conhece a respeito da estabilidade do cianeto livre na manipueira após sua liberação.

Assim, com o presente estudo objetivou-se avaliar a estabilidade de cianeto livre $\left(\mathrm{CN}^{-}\right)$na composição da manipueira em duas diferentes formas de armazenamento, visando auxiliar pesquisadores e produtores no uso mais eficiente e racional deste resíduo como um método de controle alternativo ao uso de agrotóxicos em programas de manejo fitossanitário de pragas e doenças em patossistemas agrícolas e florestais. 


\section{MATERIAL E MÉTODOS}

O trabalho foi desenvolvido no Laboratório de Epidemiologia e Manejo de doenças de Plantas Agrícolas e Florestais (LEMP), pertencente ao Núcleo de Desenvolvimento Científico e Tecnológico em Manejo Fitossanitário de Pragas e Doenças (NUDEMAFI), situado no Centro de Ciências Agrárias e Engenharias da Universidade Federal do Espírito Santo (CCAE-UFES), município de Alegre (ES), latitude $20^{\circ} 45^{\prime}$ Sul, longitude $41^{\circ} 48^{\prime}$ ' Oeste e altitude de $250 \mathrm{~m}$.

Após levantamento das variedades de mandioca produzidas, comercializadas e utilizadas pelas principais fábricas de farinha e amido da região Sul do Estado do Espírito Santo, optou-se para este trabalho o uso da mandioca variedade "Brava - Pão do Chile", a qual, no intuito de simular as etapas de beneficiamento utilizadas por estas fábricas, foi ralada, prensada manualmente e filtrada em tecido de algodão, sendo mantida em repouso por aproximadamente uma hora com o intuito de decantar o amido e resíduos sólidos ainda presentes na solução, os quais foram posteriormente descartados.

A manipueira obtida a partir da etapa anterior foi vertida em frascos tipo Erlenmeyer $250 \mathrm{~mL}$, devidamente etiquetado e armazenado em temperatura ambiente $\left(25^{\circ} \mathrm{C}\right)$ e em refrigerador $\left(6^{\circ} \mathrm{C}\right)$, durante toda a realização do experimento, sendo estas consideradas as soluções de manipueira padrão.

$\mathrm{O}$ teor de cianeto livre $(\mathrm{CN})$ foi calculado diariamente, em seis repetições, com o uso do 'teste indicador de cianeto Quantofix 0-1-3-10-30mg/L CN', durante dez dias consecutivos, com o objetivo de se avaliar a estabilidade do cianeto na solução de manipueira pura quando armazenada em temperatura ambiente e em refrigerador. O mesmo estudo foi feito com relação ao pH das soluções, a partir do uso do pHmetro 'Adamo MPA-210'. A determinação do período de avaliações levou em consideração o tempo máximo utilizado como intervalo de produção dentre as principais fábricas de farinha e amido da região, voltadas para a agricultura familiar, as quais processam a mandioca em intervalos aproximados de 10 em 10 dias.

Os resultados médios obtidos durante o estudo foram analisados com o auxílio do software R (R CORE TEAM, 2014), empregando-se as análises de variância (ANOVA) e teste de Tukey $(\mathrm{p}<0,05)$. 


\section{RESULTADOS E DISCUSSÃO}

Não houve diferença estatística significativa entre os tratamentos estudados. Este resultado pode ser justificado considerando a ausência de variação dos teores de $\mathrm{CN}^{-}$entre as repetições de cada tratamento $(\mathrm{CV}=0 \%)$, decorrente da leitura em valores fixos de 0-1-3-10-30 mg/L de $\mathrm{CN}^{-}$a partir do uso do teste indicador de cianeto livre, conforme metodologia proposta anteriormente.

A partir da análise descritiva dos dados obtidos neste estudo pode-se observar que no tempo de armazenamento zero, ou seja, logo após a extração da manipueira, a média da concentração de cianeto livre foi de $3 \mathrm{mg} \cdot \mathrm{L}^{-1}$. A concentração inicial do $\mathrm{CN}^{-}$do resíduo contrasta com a concentração de $30 \mathrm{mg} \cdot \mathrm{L}^{-1}$ obtida às 24 horas após a extração, valor este referente à máxima leitura fornecida pelo teste utilizado nas duas diferentes formas de armazenamento (Gráfico 1).

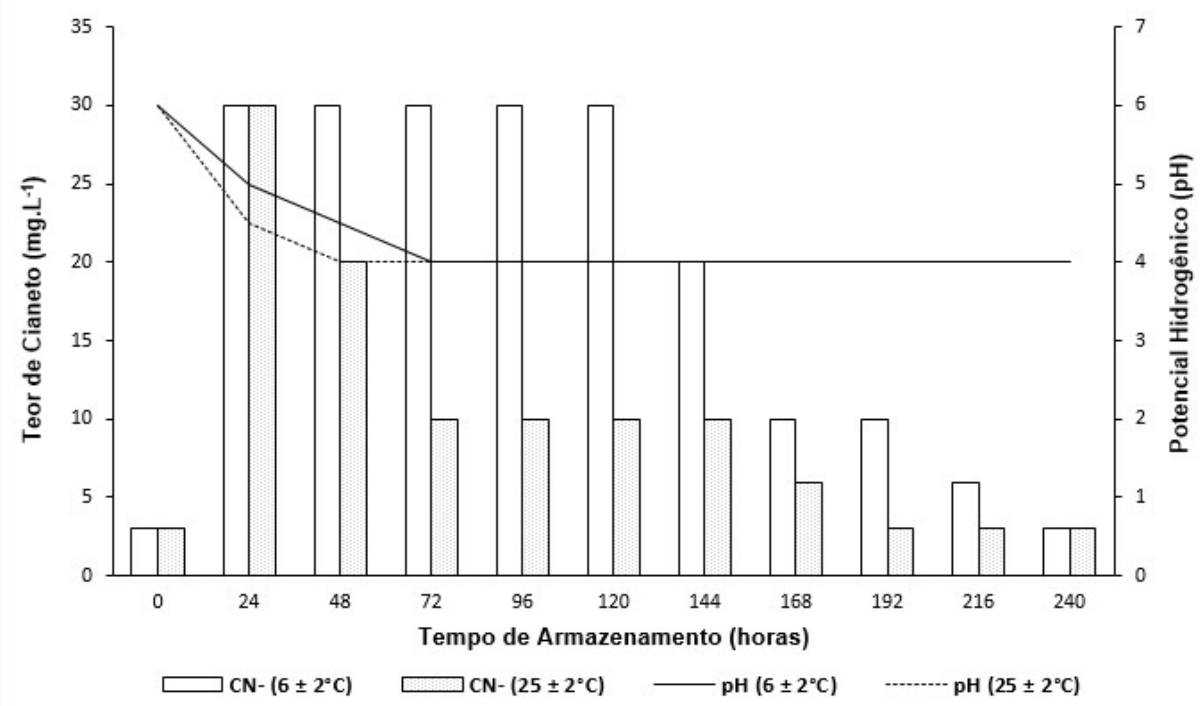

Gráfico 1. Estabilidade da concentração de cianeto livre (CN) presente em manipueira extraída de mandioca 'brava' cv. Pão do Chile e armazenada em temperatura ambiente $\left(25^{\circ} \mathrm{C}\right)$ e em refrigerador $\left(6^{\circ} \mathrm{C}\right)$, durante 240 horas. 
O contraste existente entre os valores de cianeto livre presentes nas amostras logo após a extração e os valores presentes após 24 horas justifica-se pela intensa fermentação natural dos seus constituintes, decorrente da sua extração, conforme já demonstrado por Leonel, Hamada e Cereda (1991) e Cabello (1991). Segundo Tokarnia et al. (2012), quando ocorre a lise dos tecíodos e os vacúolos celulares são rompidos, ocorre a liberação dos glicosídeos que entram em contato com a enzima linamarase, a qual é convertida em linamarina e lotaustralina formando, assim, o cianeto livre. Neste processo há, também, a elevação da acidez da manipueira.

Diversos autores estudaram a composição química da manipueira e relatam teores de $\mathrm{CN}^{-}$variando de 22 a 46 mg. $\mathrm{L}^{-1}$, também às 24 horas da extração (FIORETTO, 2001; CAGNON; CEREDA; PANTAROTO, 2002), corroborando com os dados obtidos neste experimento. Contudo, não há relatos a respeito do período de viabilidade de uso da manipueira para os mais diversos fins, mais especificamente com relação aos teores de cianeto livre presentes neste resíduo (TAKAHASHI; CEREDA, 1986; PONTE, 1992; CEREDA, 2001; NASU, 2008; NASU et al., 2010).

Com relação às diferentes temperaturas de armazenamento, os maiores teores de $\mathrm{CN}^{-}$foram obtidos, ao longo do período de avaliação, em manipueira armazenada a $6{ }^{\circ} \mathrm{C}$, na qual também foi observada maior estabilidade do cianeto livre, principalmente nas primeiras 120 horas após a extração, fato este decorrente da redução do metabolismo de microrganismos, o que leva, consequentemente, a uma menor fermentação dos carboidratos, menor liberação de enzimas e maior conservação e estabilidade da solução (CHI; ZHAO, 2003; MOREIRA; SIQUEIRA, 2002; SOLA, 2011).

Considerando o uso da manipueira para as mais diversas finalidades, com destaque para seu reaproveitamento como forma de controle alternativo ao uso de agrotóxicos em um sistema de manejo fitossanitário de pragas e doenças de plantas agrícolas, o qual possui viabilidade dependente dos teores de cianeto livre, os resultados obtidos nesta pesquisa possuem relevância por evidenciar a permanência e estabilidade de $\mathrm{CN}^{*}$ presentes no resíduo por um período maior que a manipueira armazenada em temperatura ambiente, método mais comumente utilizado. Todavia, a permanência e estabilidade de $\mathrm{CN}^{-}$na solução ao longo do tempo em manipueira armazenada em temperatura ambiente $\left(25^{\circ} \mathrm{C}\right)$, ainda que em 
concentrações inferiores em relação ao armazenamento sob refrigeração, viabiliza o seu uso a campo.

Conforme já mencionado, quando os glicosídeos tóxicos naturalmente presentes no resíduo são convertidos em linamarina e lotaustralina, com posterior formação do cianeto livre, quimicamente ácido, ocorre, simultaneamente, a elevação da acidez da manipueira. Essa afirmação pode ser comprovada ao analisarmos os valores referentes ao potencial Hidrogeniônico $(\mathrm{pH})$ obtidos logo após a extração da manipueira (escala logarítimica média referente a 6,0) com os obtidos após 240 horas de armazenamento (escala logarítimica média referente a 4,0), independentemente do método de armazenamento.

Resultados similares foram encontrados por Ferreira et al. (2001), que, após análise da manipueira fresca extraída de mandioca branca e amarela, constataram $\mathrm{pH}$ 6,30 e 6,15, respectivamente, o que também foi demonstrado por Leonel e Cereda (1995) e por Ribeiro et al. (2010). Entretanto, após 48 horas de armazenamento da manipueira, o pH das amostras reduziu para 3,87 e 3,46, respectivamente, atingindo estabilidade de 3,83 e 3,40, após 78 horas.

Apesar dos relatos anteriores, nenhum dos autores mencionados descrevem a estabilidade do $\mathrm{pH}$ da manipueira ao longo do tempo, em diferentes temperaturas de armazenamento. Tais informações tornam-se relevantes quando a finalidade de uso da manipueira tem sua aplicação principalmente via solo, seja como fonte complementar de nutrientes minerais ou como forma de controle alternativo de patógenos veiculados pelo solo. O caráter ácido da manipueira, quando aplicado sem o conhecimento dos seus constituintes, poderá acarretar diretamente na acidificação do solo, indisponibilizando micronutrientes à planta e, também, reduzindo a biota natural do solo.

Por esta razão, os dados obtidos no presente estudo servirão como base a pesquisadores e produtores na busca por metodologias de manejo de pragas e doenças mais eficientes e racionais, que objetivem atender a demanda fitossanitária do produtor em equilíbrio com a sustentabilidade do meio ambiente. O esclarecimento a respeito das condições de permanência e estabilidade do cianeto livre na solução de manipueira, assim como dos teores de acidez, auxiliará diretamente na tomada de decisão pela utilização deste resíduo como forma alternativa de controle de pragas e 
doenças e, indiretamente, na substituição a campo do uso de produtos químicos por produtos naturais, possibilitando a redução dos custos de produção e na adequada destinação final deste resíduo.

\section{CONSIDERAÇÕES FINAIS}

A manipueira possui variável estabilidade e contínua permanência do teor de cianeto livre (CN) em sua composição, dentro do período avaliado, independente da forma de armazenamento.

Os maiores teores de $\mathrm{CN}^{-}$foram observados durante as primeiras 24 horas após a extração da manipueira, sendo este o melhor período para sua utilização em manejos fitossanitários de pragas e doenças.

\section{AGRADECIMENTOS}

Agradecemos ao Conselho Nacional de Desenvolvimento Científico e Tecnológico (CNPq - Brasília (DF), Brasil) e à Coordenação de Aperfeiçoamento de Pessoal de Nível Superior (CAPES - Brasília (DF), Brasil) pelo apoio financeiro concedido.

\section{REFERÊNCIAS}

ALMEIDA, N. S.; CARMO, D. O.; SOUZA, J. T.; SOARES, A. C. F. Efeito da manipueira no controle de Scutellonema bradys e na germinação de túberas de inhame. Fitopatologia Brasileira, v. 32, supl., p. 234, 2007.

ALVES, E. C.; SANTIAGO, A. D.; ELOY, A. P.; AMORIM, E. P. R. Efeito tóxico da manipueira sobre Scutellonema bradys, causador da "casca-preta" no inhame (Dioscorea cayennensis). Fitopatologia Brasileira, n. 31, 2006.

BALDIN, E. L. L.; WILCKEN, S. R. S.; PANNUTI, L. E. da R.; SCHLICK-SOUZA, C.; VANZEI, F. P. Uso de extratos vegetais, manipueira e nematicida no controle do nematoide das galhas em cenoura. Summa Phytopatbologica, v. 38, n. 1, p. 36$41,2012$. 
CABELLO, C. Avaliação do substrato manipueira na biossíntese de ácido cítrico monitorada por computador. 1991. 88 f. Dissertação (Mestrado em Energia na Agricultura) - Faculdade de Ciências Agronômicas, Universidade Estadual Paulista, Botucatu, 1991.

CAGNON, J. R.; CEREDA, M. P.; PANTAROTO, S. Glicosídeos cianogênicos da mandioca: biossíntese, distribuição, destoxificação e métodos de dosagem. In: CEREDA, M. P. Agricultura: tuberosas amiláceas latino americanas. São Paulo: Cargill, 2002. p. 83-99.

CASSONI, V.; CEREDA, M. P. Avaliação do processo de fermentação acética da manipueira. Energia na Agricultura, v. 26, n. 4, p. 101-113, 2011.

CEREDA, M. P. Caracterização dos subprodutos da industrialização da mandioca. In: CEREDA, M. P. Manejo, uso e tratamento de subprodutos da industrialização da mandioca. São Paulo: Cargill, 2001. p. 13-37.

CHI, Z.; ZHAO, S. Optimization of medium and cultivation conditions for pullulan production by a new pullulan-producing yeast strain. Enzyme and Microbial Technology, v. 33, p. 206-211, 2003.

COMERLATO, A. P. Efeito de manipueira no controle do nematoide de cisto da soja Heterodera glycines Ichinohe. 2009. 47 f. Dissertação (Mestrado em Agronomia) - Universidade Estadual do Oeste do Paraná, Cascavel, 2009.

DAMASCENO, J. C. A.; RITZINGER, C. H. S. P.; RITZINGER, R.; VIEIRA, R. S.; LEDO, C. A. S. Ação da manipueira no controle de nematoides em mudas de mamoeiro. In: CONGRESSO BRASILEIRO DE FRUTICULTURA, 20., 2008, Vitória. Anais [...]. Vitória: Incaper, 2008. p. 54.

FIORETTO, R. A. Uso direto da manipueira em fertirrigação: manejo, uso e tratamento de subprodutos da industrialização da mandioca. São Paulo: Cargill, 2001. p. 13-37.

FONSECA, W. L.; ALMEIDA, F. A. de; OLIVEIRA, A. M. de; LEITE, M. L. T.; PROCHNOW, J. T.; RAMOS, L. da L. Toxicity of manipueira to Meloidogyne incógnita in 
soybean. Pesquisa Agropecuária Tropical, v. 46, n. 4, p. 413-420, 2016.

FREIRE, F. das C. O. Uso da manipueira no controle de oídeo na cerigueleira: resultados preliminares. Fortaleza: Ministério da Agricultura, Pecuária e Abastecimento, 2001. (Comunicado Técnico, n. 70).

FURLANETTO, C.; ESTEVES, R. L.; COMERLATO, A. P.; NASU, E. G. C.; FORMENTINI, H. M. Manipueira: um potente nematicida no controle de nematoides. In: CONGRESSO BRASILEIRO DE NEMATOLOGIA, 29., 2011. Anais [...]. Brasília: UNB, 2011. p. 114-119.

GONZAGA, A. D.; GARCIA, M. V. B.; SOUZA, S. G. A.; PY-DANIEL, V.; CORREA, R. S.; RIBEIRO, J. D. Toxicidade de manipueira de mandioca (Manibot esculenta Crantz) e erva-de-rato (Palicourea marcgravii St. Hill) a adultos de Toxoptera citricida Kirkaldy (Homoptera: Apbididae). Acta Amazonica, v. 38, n. 1, p. 101-106, 2008.

LEONEL, M.; CEREDA, M. P. Manipueira como substrato na biossíntese de ácido cítrico por Aspergillus niger. Scientia Agricola, v. 52, n. 2, p. 299-304, 1995.

LEONEL, M.; HAMADA, C.; CEREDA, M. P. Cultivo de Aspergillus niger em água residual de processamento de mandioca (manipueira). In: CONGRESSO BRASILEIRO DE MICROBIOLOGIA, 16., 1991, Santos. Anais [...]. 1991. p. 215.

LINARDI, V. R. Degradação biológica de cianetos: a importância do desenvolvimento de tecnologia para obtenção de um tratamento biológico. Disponível em: http://www.biotecnologia.com.br. Acesso em: 3 jun. 2000.

MOREIRA, F.; SIQUEIRA, J. O. Microbiologia e bioquímica do solo. Larvas: UFLA, 2002. $623 \mathrm{p}$.

PIMENTA, C. A. M.; CARNEIRO, R. M. D. G. Utilização Pasteuria penetrans em controle biológico de Meloidogyne javanica em duas culturas sucessivas de alface e tomate. Brasília: EMBRAPA, 2005. p. 36.

PONTE, J. J. Cartilha da manipueira: uso do composto como insumo agrícola. Fortaleza: Governo do Estado do Ceará: Secretaria da Ciência e Tecnologia, 1999. 
PONTE, J. J. da. Histórico das pesquisas sobre utilização da manipueira (extrato líquido de raízes de mandioca) como defensivo agrícola. Fitopatologia Venezuelana, v. 5 , n. 2 , p. $2-5,1992$.

PRATIS, S. B. Q.; WENGRAT, A. P. G. S.; CASSIANO, A. D.; FREDRICH, J. E.; PIETROWSKI, V.; LEDO, C. A. D. Aplicação de manipueira no controle da cochonilha da raiz (Dysmicoccus sp.). In: CONGRESSO BRASILEIRO DE MANDIOCA, 15. 2013, Salvador. Anais [...]. Salvador: Sociedade Brasileira de Mandioca, 2013.

R CORE TEAM. R: a language and environment for statistical computing. Vienna, Austria: R Foundation for Statistical Computing, 2014.

SILVA, C. A.; SOUZA, T. S. O.; SILVA, A. S. Potencial de uso da manipueira como alternativa de controle de Spodoptera frugiperda em milho. In: CONGRESSO LATINO AMERICANO DE AGROECOLOGIA, 6., 2017, Brasília. Anais [...]. Brasília: Associação Brasileira de Agroecologia: Sociedad Latinoamericana de Agroecología, 2017.

SOLA, M. C. Manutenção de microrganismos: conservação e viabilidade. Goiânia: UFG, 2011. 34 p.

TOKARNIA, C. H. et al. Plantas tóxicas do Brasil para animais de produção. 2. ed. Rio de Janeiro: Helianthus, 2012. p. 443-459.

Recebido em: 01/12/2017

Aceito em: 28/08/2018 